\title{
Transfer Reaction of the Two Propagating Species in Cationic Polymerization of Styrene by Acetyl Perchlorate or Trifluoromethanesulfonic Acid
}

\author{
Takashi Takeda, Mitsuo Sawamoto, and Toshinobu Higashimura \\ Department of Polymer Chemistry, Faculty of Engineering, \\ Kyoto University, Kyoto 606, Japan.
}

(Received February 8, 1977)

\begin{abstract}
The transfer reaction of two differently dissociated propagating species towards $m$-xylene and methanol was investigated in the cationic polymerization of styrene by acetyl perchlorate or trifluoromethanesulfonic acid where the two species coexist. Transfer constants $\left(k_{\mathrm{tx}} / k_{\mathrm{p}}\right)$ for these dissociated and nondissociated species were determined from the dependence of a bimodal molecular weight distribution of polymers on the transfer agent concentration. It was found that in $\mathrm{CH}_{2} \mathrm{Cl}_{2}$ the transfer constant for the nondissociated species is larger than that for the dissociated one. The latter value increased when the dissociation of the propagating species was suppressed by addition of a common-ion salt $\left(n \mathrm{Bu}_{4} \mathrm{NClO}_{4}\right)$ or a nonpolar solvent $\left(\mathrm{CCl}_{4}\right)$. Dependence of the transfer constant on the nature and reactivity of the propagating species was discussed.
\end{abstract}

KEY WORDS Cationic Polymerization / Styrene / Propagating Species / Transfer Reaction / Molecular Weight Distribution / Acetyl Perchlorate / Trifluoromethanesulfonic Acid /

The cationic polymerizations of styrene and its derivatives by acetyl perchlorate $\left(\mathrm{AcClO}_{4}\right),{ }^{1-3}$ perchloric acid $\left(\mathrm{HClO}_{4}\right),{ }^{2,4,5}$ and trifluoromethanesulfonic acid $\left(\mathrm{CF}_{3} \mathrm{SO}_{3} \mathrm{H}\right)^{6,7}$ produce polymers having a bimodal molecular weight distribution (MWD). Our previous work $^{1-3,6,7}$ has shown that the bimodal MWD is due to the independent and simultaneous propagation of two species, one of which, giving the low polymer, is "nondissociated" and the other, forming the high polymer, is "dissociated."

These two propagating species being different in the dissociation state are expected also to differ in reactivity and selectivity in polymerization. We have already found that the polymerization reactivity of the dissociated species is higher than that of the nondissociated one, ${ }^{2,7}$ and that their relative reactivities towards two monomers in copolymerization depend upon their dissociation state.

In this investigation, their relative reactivities towards reagents which can give different ionic species from the propagating species are further compared in a transfer reaction. Styrene is used as a monomer, and $m$-xylene and methanol as transfer agents. The aromatic ring of $m$ xylene will undergo a Friedel-Crafts reaction with the propagating species; ${ }^{10}$ methanol may react through its oxygen atom.

\section{EXPERIMENTAL}

\section{Materials}

Commercial $m$-xylene was purified in the usual manner and distilled over calcium hydride before use. Its purity was more than $99.9 \%$ (by gas chromatography). Commercial methanol (spectroscopic grade, purity $\geq 99 \%$ ) was used without further purification. $\mathrm{AcClO}_{4}$ was synthesized by the method previously described. ${ }^{11} \quad \mathrm{CF}_{3} \mathrm{SO}_{3} \mathrm{H}$ (Sumitomo 3M Co., purity $\geq 98 \%$ ) was used without any purification. Monomer and solvents were purified in the usual manner. 


\section{Procedures}

Styrene was polymerized at $0^{\circ} \mathrm{C}$ in the presence of a transfer agent at various concentrations in a flask equipped with a stopcock under a dry nitrogen atomosphere. ${ }^{2}$ The polymerizations were made to stop by the addition of methanol at the point of a $20-30 \%$ conversion. To recover the polymers produced, the polymerization solution brought to a standstill, was evaporated to dryness under reduced pressure at $c a .40^{\circ} \mathrm{C}$. The MWD of the polymers was measured by gel-permeation chromatography (GPC) on a Shimazu Model GPC-700 equipped with polystyrene gel columns (SG-1, 2, 3, 4, and 5). 2Butanone was used as the eluent for GPC measurements.

The peak molecular weight (the molecular weight at the peak of a MWD curve) was taken for convenience as the number-average molecular weight $\left(\bar{M}_{n}\right)$ of the polymers. The peak molecular weight is proportional to $\bar{M}_{n}$, if the MWD is Gaussian (or logarithmic normal). ${ }^{12}$ We did not calculate $\bar{M}_{n}$ values directly from measured distribution curves, because for polymer mixtures containing low molecular weight polymer and oligomers, $\bar{M}_{n}$ values thus obtained are usually erroneous. When a MWD was bimodal, it was resolved into two Gaussian curves by means of a du Pont curve resolver to determine the peak molecular weight of each fraction.

\section{RESULTS AND DISCUSSION}

\section{Transfer Constants for the Two Propagating} Species

Polystyrenes obtained by $\mathrm{AcClO}_{4}$ or $\mathrm{CF}_{3} \mathrm{SO}_{3} \mathrm{H}$ in methylene chloride $\left(\mathrm{CH}_{2} \mathrm{Cl}_{2}\right)$ at $0^{\circ} \mathrm{C}$ show a bimodal MWD. To these systems various amounts of $m$-xylene $(0.12-0.41 M)$ or methanol $(2.0-6.0 \mathrm{~m} M)$ were added and the MWD of resultant polymers was measured. In order to hold the dielectric constant of the solution constant, $m$-xylene was added with carbon tetrachloride keeping their total concentration at 5.0 vol $\%$. This procedure was not applied for methanol, because its volume was negligibly small.

Figure 1 shows the MWD of the polymers obtained by $\mathrm{AcClO}_{4}$ in the presence of $m$-xylene

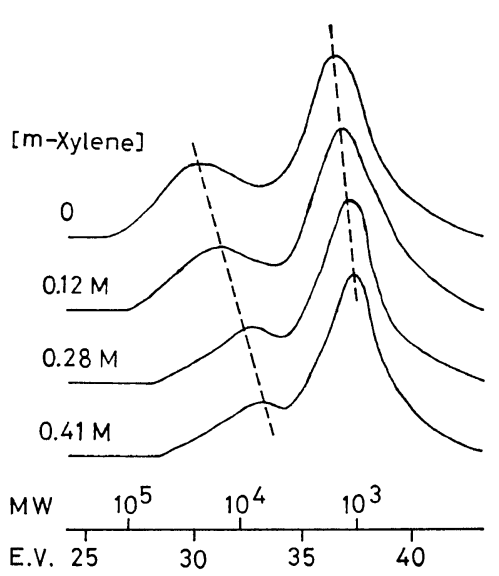

Figure 1. Effect of $m$-xylene on the molecular weight distribution of polystyrenes produced by $\mathrm{AcClO}_{4}$ in $\mathrm{CH}_{2} \mathrm{Cl}_{2}$ at $0^{\circ} \mathrm{C}:[\mathrm{M}]_{0}=1.0 \mathrm{M} ;[\mathrm{C}]_{0}=$ $0.40 \mathrm{mM}$; conversion, $20-30 \%$; $m$-xylene $+\mathrm{CCl}_{4}=$ $5.0 \mathrm{vol} \%$.

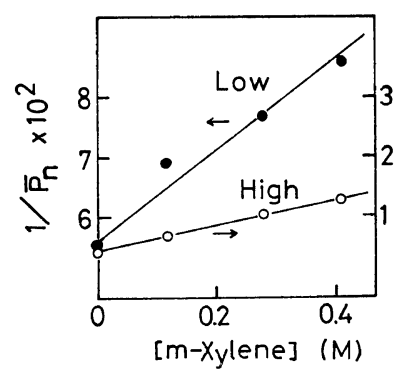

Figure 2. Plots of the Mayo equation for the high and the low polymers (transfer agent, $m$ xylene). Polymerization conditions are the same as in Figure 1: High, the high polymer; low, the low polymer.

as the transfer agent. The MWD was always bimodal, but both the high and low polymer peaks shifted to the low molecular weight side as the $m$-xylene concentration increased.

The bimodal MWD was resolved into the high and low molecular weight portions and their molecular weights were plotted according to the Mayo equation

$$
\frac{1}{\bar{P}_{n}}=\frac{1}{\bar{P}_{0}}+\frac{k_{\mathrm{tx}}[\mathrm{X}]}{k_{\mathrm{p}}[\mathrm{M}]}
$$

where $\bar{P}_{n}$ and $\bar{P}_{0}$ are the number-average degrees of polymerization in the presence and absence of a transfer agent $\mathrm{X}$, respectively. Plots 
Transfer Reaction in Cationic Polymerization

Table I. Transfer constants $\left(k_{\mathrm{tx}} / k_{\mathrm{p}}\right)$ for the high and the low polymers in $\mathrm{CH}_{2} \mathrm{Cl}_{2}{ }^{\mathrm{a}}\left([\mathrm{M}]_{0}, 1.0 \mathrm{M}\right.$; $\left[\mathrm{AcClO}_{4}\right], 0.40 \mathrm{mM} ;\left[\mathrm{CF}_{3} \mathrm{SO}_{3} \mathrm{H}\right], 0.20 \mathrm{mM}, 0^{\circ} \mathrm{C}$ )

\begin{tabular}{|c|c|c|}
\hline $\begin{array}{c}\text { Transfer } \\
\text { agent }\end{array}$ & $\mathrm{AcClO}_{4}$ & $\mathrm{CF}_{3} \mathrm{SO}_{3} \mathrm{H}$ \\
\hline \multirow[t]{2}{*}{$m$-xylene } & (H) $\quad 2.1 \times 10^{-2}$ & (H) $\quad 1.3 \times 10^{-2}$ \\
\hline & (L) $7.4 \times 10^{-2}$ & (L) $3.6 \times 10^{-2}$ \\
\hline \multirow[t]{2}{*}{$\mathrm{CH}_{3} \mathrm{OH}$} & (H) 1.1 & \\
\hline & (L) 4.7 & \\
\hline
\end{tabular}

a $\mathbf{H}$, the high polymer; $\mathrm{L}$, the low polymer.

for both the high and the low polymers were linear (Figure 2), and from their slopes transfer constants $\left(k_{\mathrm{tx}} / k_{\mathrm{p}}\right)$ were determined. The value $\left(7.4 \times 10^{-2}\right)$ for the low polymer is about 3.5 times that $\left(2.1 \times 10^{-2}\right)$ for the high polymer. The transfer constants with the other initiator $\left(\mathrm{CF}_{3} \mathrm{SO}_{3} \mathrm{H}\right)$ or transfer agent (methanol) were similarly determined and the results are listed in Table I. The transfer constants for the low polymer are several times those for the high polymer irrespective of the kinds of initiator or transfer agent. This can be related to the fact that in the styrene polymerization by $\mathrm{HClO}_{4}{ }^{4}$ or $\mathrm{CF}_{3} \mathrm{SO}_{3} \mathrm{H}^{7}$ under similar conditions, the monomer transfer constant for the low polymer is larger than that for the high polymer. The transfer constants with methanol are about fifty times those with $m$-xylene. The same trend has been reported for the polymerization by metal halide initiators. ${ }^{13,14}$

\section{Dependence of Transfer Constants on the Dissoci-} ation of the Propagating Species

Only the low polymer is produced in $\mathrm{CH}_{2} \mathrm{Cl}_{2}$ containing the common-ion salt $\left(n \mathrm{Bu}_{4} \mathrm{NClO}_{4}\right.$, $0.25 \mathrm{mM}$ ) or a small amount of nonpolar solvent $\left(\mathrm{CCl}_{4}\right)$. The transfer constants with $m$-xylene under such conditions are listed in the last column of Table II.

Table II shows that when the dissociation of the propagating species is suppressed by the addition of the salt or the nonpolar solvent, the transfer constants are larger than that for the high polymer obtained in $\mathrm{CH}_{2} \mathrm{Cl}_{2}$. In particular, the constant in the mixture of $\mathrm{CH}_{2} \mathrm{Cl}_{2} / \mathrm{CCl}_{4}(5 / 1, \mathrm{v} / \mathrm{v})$ agrees fairly well with that for the low polymer produced in $\mathrm{CH}_{2} \mathrm{Cl}_{2}$ (cf. Table I).
Table II. Effect of the dissociation of the propagating species on transfer constants $\left(k_{\mathrm{tx}} / k_{\mathrm{p}}\right)^{\mathrm{a}}$ (transfer agent, $m$-xylene; $[\mathrm{M}]_{0}, 1.0 \mathrm{M}$; $\left[\mathrm{AcClO}_{4}\right], 0.40 \mathrm{mM}, 0^{\circ} \mathrm{C}$ )

\begin{tabular}{lcc}
\hline \multirow{2}{*}{ Solvent-Salt } & \multicolumn{2}{c}{$k_{\mathrm{tx}} / k_{\mathrm{p}}$} \\
\cline { 2 - 3 } & $(\mathrm{H})$ & $(\mathrm{L})$ \\
\hline $\mathrm{CH}_{2} \mathrm{Cl}_{2} / \mathrm{CCl}_{4}(5 / 1)$ & - & $6.7 \times 10^{-2}$ \\
$\mathrm{CH}_{2} \mathrm{Cl}_{2}-n \mathrm{Bu}_{4} \mathrm{NClO}_{4}$ & - & $4.7 \times 10^{-2}$ \\
$\mathrm{PhNO}_{2}$ & $6.7 \times 10^{-2}$ & - \\
$\mathrm{PhNO}_{2}-n \mathrm{Bu}_{4} \mathrm{NClO}_{4}$ & $6.7 \times 10^{-2}$ & - \\
\hline
\end{tabular}

a $\mathrm{H}$, the high polymer; L, the low polymer.

Transfer constants in a polar solvent, such as nitrobenzene $\left(\mathrm{PhNO}_{2}\right)$, in which only the high polymer was produced, were also determined (transfer agent: $m$-xylene, see Table II). It is supposed $^{2}$ that under such conditions, the propagating species is the dissociated one, which is similar to that forming the high polymer in $\mathrm{CH}_{2} \mathrm{Cl}_{2}$. As Table II shows, the transfer constant in nitrobenzene did not change on addition of excess common-ion salt, although the salt should have suppressed the dissociation of the propagating species. This implies that the nature of an ion pair in nitrobenzene is completely different from that in $\mathrm{CH}_{2} \mathrm{Cl}_{2}$. On the basis of the steric structure of polymers ${ }^{15}$ and salt effects on copolymerization, ${ }^{8,9}$ we previously speculated that the ion pair in nitrobenzene on salt addition might be a solvent-separated ion pair, differing from the (probably contact) ion pair in $\mathrm{CH}_{2} \mathrm{Cl}_{2}$. The above results agree with this speculation. However, the transfer constant in nitrobenzene is much larger than that for the dissociated species in $\mathrm{CH}_{2} \mathrm{Cl}_{2}$. This discrepancy may suggest that the dissociated species are differently solvated in the two solvents, although further investigation is needed to interpret these facts.

The following has been shown in the present study: The two propagating species producing the high and the low polymers have definitely different transfer constants towards $m$-xylene and methanol; the latter (nondissociated) species possesses a larger value than the former (dissociated) one. This result is inconsistent with the generally accepted reactivity-selectivity relationship that a more reactive species has closer 
relative reactivities towards the two reagents. Dorfman, et al., ${ }^{16}$ have reported that in the protonation of free and ion-paired benzyl carbanion in tetrahydrofuran, the ion pair is more reactive than the free ion. Since the reaction may give a product on which the negative charge is substantially localized, they interpreted the enhanced reactivity of the ion pair as due to some stabilization of the transition state by coulombic interaction between the counterion and the charge. The ion produced from $m$ xylene or methanol may have more localized positive charge than the propagating species (polystyryl carbenium ion). Therefore, the similar interpretation to above might be applicable to our result.

\section{REFERENCES}

1. T. Masuda and T. Higashimura, J. Polym. Sci., Part B, 9, 783 (1971).

2. T. Higashimura and O. Kishiro, ibid., Polym. Chem. Ed., 12, 967 (1974).

3. T. Higashimura, O. Kishiro, and T. Takeda, ibid., 14, 1089 (1976).
4. D. C. Pepper, ibid., Polym. Symp., 50, 51 (1975).

5. D. C. Pepper, Makromol. Chem., 175, 1077 (1974).

6. T. Masuda, M. Sawamoto, and T. Higashimura, ibid., 177, 2981 (1976).

7. M. Sawamoto, T. Masuda, and T. Higashimura, ibid., 177, 2995 (1976).

8. K. Yamamoto and T. Higashimura, J. Polym. Sci., Polym. Chem. Ed., 14, 2621 (1976).

9. T. Higashimura and K. Yamamoto, ibid., 15, 301 (1977).

10. C. G. Overberger, G. F. Endres, and A. Monaci, J. Am. Chem. Soc., 78, 1969 (1956).

11. T. Masuda and T. Higashimura, J. Macromol. Sci.-Chem., A5, 547 (1971).

12. H. L. Berger and A. R. Shultz, J. Polym. Sci., 3, 3643 (1965).

13. C. G. Overberger and M. C. Newton, J. Am. Chem. Soc., 82, 3622 (1960).

14. T. Higashimura and S. Okamura, Kobunshi Kagaku (Chem. High Polymers), 17, 57 (1960).

15. T. Higashimura, T. Takeda, M. Sawamoto, K. Matsuzaki, and T. Uryu, J. Polym. Sci., Polym. Chem. Ed., in press.

16. L. M. Dorfman, R. J. Sujdak, and B. Bockrath, Acc. Chem. Res., 9, 352 (1976), and references cited therein. 